\title{
Regulation of steroidogenesis in fetal bovine ovaries: differential effects of LH and FSH
}

\author{
J J Allen, S L Herrick and J E Fortune \\ Department of Biomedical Sciences, Cornell University, Ithaca, New York, USA
}

Correspondence should be addressed to $J J$ Allen Email

jja63@cornell.edu

\begin{abstract}
In cattle, primordial follicles form before birth. Fetal ovarian capacity to produce progesterone and estradiol is high before follicle formation begins and decreases around the time follicles first appear (around 90 days of gestation). However, mechanisms that regulate steroid production during this time remain unclear. We hypothesized that $\mathrm{LH}$ stimulates progesterone and androgen production and that FSH stimulates aromatization of androgens to estradiol. To test this, we cultured pieces from fetal bovine ovaries for 10 days without or with exogenous hormones and then measured the accumulation of steroids in the culture medium by RIA. LH $(100 \mathrm{ng} / \mathrm{mL})$ alone increased the accumulation of progesterone, androstenedione, testosterone and estradiol. FSH $(100 \mathrm{ng} / \mathrm{mL})$ alone increased both progesterone and estradiol accumulation, but had no effect on androgens. Exogenous testosterone $(0.5 \mu \mathrm{M})$ alone greatly increased estradiol accumulation and the combination of testosterone $+\mathrm{FSH}$, but not testosterone $+\mathrm{LH}$, increased estradiol relative to testosterone alone. Interestingly, exogenous testosterone and estradiol decreased progesterone accumulation in a dose-dependent manner. Because the highest dose of estradiol $(0.5 \mu \mathrm{M})$ decreased progesterone accumulation, but increased both pregnenolone and androstenedione in the same cultures, endogenous estradiol may be a paracrine regulator of steroid synthesis. Together, these results confirm our initial hypotheses and indicate that LH stimulates androgen production in fetal bovine ovaries via the $\Delta^{5}$ pathway, whereas FSH stimulates aromatization of androgens to estradiol. These results are consistent with the two-cell, two-gonadotropin model of estradiol production by bovine preovulatory follicles, which suggests that the mechanisms regulating ovarian steroid production are established during fetal life.
\end{abstract}

Key Words
LH
- FSH
- steroidogenesis
- fetal ovary
- cattle

Journal of Molecular

Endocrinology

(2016) 57, 275-286

\section{Introduction}

A pool of non-growing, primordial follicles supplies female mammals with oocytes throughout reproductive life, and thus affects their reproductive potential. Despite the importance of the primordial pool to reproductive success, the mechanism(s) regulating its formation and size are poorly understood, particularly in non-rodent species. Primordial follicles remain quiescent for variable lengths
() 2016 Society for Endocrinology Printed in Great Britain of time before they initiate growth (activate). During follicle activation, the transition from resting primordial to growing primary follicle, the oocyte begins to grow and the squamous granulosa cells become cuboidal in shape. In rodents, follicles form in a synchronous fashion shortly after birth (Kezele \& Skinner 2003, Pepling 2006). In contrast, follicles form during early-to-mid-gestation in

Published by Bioscientifica Ltd 
humans (Baker 1963), cattle (Erickson 1966, Russe 1983, Tanaka et al. 2001, Yang \& Fortune 2008, Garverick et al. 2010) and sheep (Russe 1983, Sawyer et al. 2002), making follicle formation difficult to study in these species. Cattle are not only an economically important species but also an excellent model for early follicular development in humans because the length of gestation and the timing of folliculogenesis in fetal ovaries are similar in the two species (Campbell et al. 2003). Our lab observed the first primordial and primary follicles in fetal bovine ovaries around 90 and 140 days of gestation, respectively (Yang \& Fortune 2008), consistent with the findings of Rüsse (1983) and Dominguez and coworkers (1988), but the timing in other reports differs (Erickson 1966, Tanaka et al. 2001, Nilsson \& Skinner 2009, Garverick et al. 2010).

Factors that regulate follicle formation and activation in utero are of practical importance for humans and domestic species because they affect the size of the primordial pool at birth, and hence, the female's reproductive potential. Progesterone and estradiol inhibit primordial follicle formation in neonatal mouse ovaries, both in vitro and in vivo (Chen et al. 2007). In cattle, exogenous progesterone and estradiol inhibit both follicle formation and the capacity of primordial follicles to activate in vitro (Yang \& Fortune 2008, Nilsson \& Skinner 2009, Fortune et al. 2010). Interestingly, fetal ovarian capacity to produce progesterone and estradiol decreases around the time follicles form in cattle, and these steroids remain low while the first growing follicles appear (Dominguez et al. 1988, Yang \& Fortune 2008, Nilsson \& Skinner 2009). These results support the hypothesis that fetal ovarian estradiol and progesterone are important negative regulators of follicle formation and activation in vivo, but little is known about the mechanisms that regulate steroidogenesis during fetal life, particularly at this critical time of development.

In adult mammalian ovaries, the production of sex steroids from cholesterol is regulated by the gonadotropins, luteinizing hormone (LH) and follicle-stimulating hormone (FSH). The two-cell, two-gonadotropin model describes estradiol synthesis in preovulatory follicles of cattle and other mammalian species. In brief, LH stimulates the production of androgens by theca cells, whereas FSH stimulates granulosa cells to convert thecal androgens to estrogens via the enzyme aromatase (reviewed in Fortune \& Quirk 1988). Immunohistochemical studies localized protein for aromatase in fetal bovine ovaries between 45 and 250 days of gestation (Burkhart et al. 2010, Garverick et al. 2010), and gonadotropins are present in the serum of bovine fetuses of similar ages (Oxender et al. 1972b, Challis et al. 1974, Tanaka et al. 2001, Muranishi et al. 2002). Ovaries from 120- to 260-day-old bovine fetuses have binding sites for LH and FSH (Wandji et al. 1992), but there is no information about ovaries of younger fetuses. Based on these results, it seems likely that gonadotropins regulate the production of steroids by fetal ovaries in vivo. In support of this, LH increased estradiol accumulation in 24-h cultures of fetal bovine ovarian pieces relative to control (Shemesh \& Hansel 1983). There is a paucity of information on the role of FSH in fetal bovine ovaries, but FSH stimulates aromatase activity in fetal ovaries of other mammals (reviewed in Weniger 1990), particularly when androgen substrate is provided. Aromatization of exogenous androgens by fetal ovaries in vitro was also observed in the absence of FSH (Shemesh 1980, Weniger 1990, Juarez-Oropeza et al. 1993). Estradiol synthesis requires androgen precursors, but the regulation of androgen production in fetal ovaries is poorly understood. However, treatment of fetal bovine ovarian tissue in vitro with steroid precursors (Juarez-Oropeza et al. 1993) or 8-Br-cAMP (Shemesh 1980) increased the accumulation of testosterone in the culture medium, indicating that fetal bovine ovaries have the capacity to produce androgens.

Mechanisms that regulate steroid production by fetal ovaries are critical to our understanding of ovarian development, especially in larger mammals (e.g. humans, cattle and sheep), but progress in this field has been limited. The existing evidence indicates that $\mathrm{LH}$, and perhaps FSH, can regulate fetal ovarian steroidogenesis. Therefore, the objective of these studies was to test the hypothesis that LH stimulates progesterone and androgen production by fetal bovine ovaries, whereas FSH stimulates the conversion (aromatization) of androgens to estrogens. Because cattle are an excellent model for human ovarian development (Campbell et al. 2003), results from these studies might be relevant to both other ruminants and humans.

\section{Materials and methods}

\section{Culture of fetal bovine ovarian pieces}

Ovaries were dissected from fetuses (primarily Holstein) between 74 and 114 days after conception $(11.5-24 \mathrm{~cm}$ crown rump length (Rexroad et al. 1974)) because follicles form around Day 90 in vivo, coincident with decreases in capacity of fetal ovaries to produce progesterone and estradiol (Yang \& Fortune 2008, Nilsson \& Skinner 2009). Experiments were replicated with at least three

Published by Bioscientifica Ltd. 
fetuses obtained on separate occasions at a local slaughterhouse (Cargill Regional Beef; Wyalusing, PA, USA). Preparation and culture of ovarian tissue are described in detail elsewhere (Yang \& Fortune 2008, Wandji et al. 1996). In brief, ovaries were transported to the lab at ambient temperature in Leibovitz L-15 medium (Life Technologies) supplemented with 1\% FBS, $50 \mathrm{IU} / \mathrm{mL}$ penicillin and $50 \mu \mathrm{g} / \mathrm{mL}$ streptomycin sulfate (Life Technologies). Ovaries were then cut into pieces $\left(\sim 1 \mathrm{~mm}^{3}\right)$, and the pieces were cultured in wells of 24-well Costar culture plates (two pieces/well; two wells/treatment/fetus) in $300 \mu \mathrm{L}$ of culture medium for 10 days at $38.5^{\circ} \mathrm{C}$ in a humidified incubator gassed with $5 \% \mathrm{CO}_{2}-95 \%$ air.

Control culture medium was Waymouth Medium MB 752/1 (Life Technologies) supplemented with $25 \mathrm{mg} / \mathrm{L}$ pyruvic acid (Sigma-Aldrich), antibiotics $(50 \mathrm{IU} / \mathrm{mL}$ penicillin $\mathrm{G}$ and $50 \mu \mathrm{g} / \mathrm{mL}$ streptomycin sulfate) and ITS+ $(6.25 \mu \mathrm{g}$ insulin, $6.25 \mu \mathrm{g}$ transferrin, $6.25 \mathrm{ng}$ selenous acid, $1.25 \mathrm{mg}$ BSA and $5.35 \mu \mathrm{g}$ linoleic acid per $\mathrm{mL}$; Corning). Ovine FSH (NIADDK o-FSH17, lot AFP6446C) and LH (NIADDK o-LH26, lot AFP5551B) were used. Stock solutions of testosterone, estradiol, $5 \alpha$-dihydrotestosterone (DHT) and androstenedione were prepared in 100\% ethanol. The aromatase inhibitor letrozole (Sigma-Aldrich) was resuspended at $0.1 \mathrm{M}$ in DMSO per manufacturer's instructions. Stock solutions of hormones and inhibitors were diluted to desired concentrations in control medium. Solvent (ethanol and/or DMSO) was added to the culture medium as needed to normalize the amount of solvent in all treatments. Culture medium was collected and replaced every 2 days and stored in frozen form for analysis of steroids by radioimmunoassay (RIA).

\section{Measurement of steroids}

Concentrations of progesterone, estradiol, androstenedione, testosterone and/or pregnenolone in unextracted culture medium were measured by RIA as described previously (Berndtson et al. 1995b, Fortune $\&$ Eppig 1979). Duplicate aliquots of 5-50 $\mu \mathrm{L}$ of culture medium were assayed and samples were diluted when necessary to ensure that measurements were within the range of the standard curve. Culture medium was added to standard curves to control for potential cross-reactivity between the antibody and components of the medium. Sensitivity of assays was $6.25 \mathrm{pg} / \mathrm{tube}$ for pregnenolone, progesterone, androstenedione and testosterone and $2.5 \mathrm{pg} /$ tube for estradiol. Inter-assay coefficients of variation (COVs) for pregnenolone, progesterone, androstenedione, testosterone and estradiol RIAs were 7.2, 9.3, 8.9, 8.6 and 9.3\%, respectively, and intra-assay COVs were 5.8, 7.3, 6.2, 7.5 and $8 \%$, respectively. Cross-reactivities of the antibodies used were described previously (Fortune \& Hansel 1985). Concentrations of steroids were determined in the culture medium collected on days 2, 4, 6, 8 and 10 of culture (every 2 days). Values are expressed as ng/ well (i.e. ng per $300 \mu \mathrm{L}$ culture medium) because this is a direct reflection of steroid content.

\section{Statistics}

Experiments were replicated with 3-7 fetuses obtained on separate occasions, and treatments were applied to duplicate culture wells for each fetus ( $n=2$ wells per treatment per fetus). To calculate the cumulative steroid produced over 10 days, values for each steroid were summed over time. Heterogeneity of variance was evaluated with Hartley's test, followed by log transformation of data sets with heterogeneity of variance. Data were then analyzed by ANOVA in SAS v9.3 using the generalized linear model (GLM) procedure. Data presented are mean \pm s.E.M. of non-transformed data. Standard errors shown in histograms include intrafetus variability (culture well), but only treatment and fetus were retained as model variables for analysis. When a significant effect of treatment was found $(P<0.05)$, differences between means were determined using Duncan's multiple range test. A wide range of ages was used in Experiment 1 (74-114 days), but there was no significant effect of fetal age on the response of ovarian pieces to hormonal treatment.

\section{Results}

Experiment 1: Effects of gonadotropins and testosterone on the production of progesterone and estradiol

We hypothesized that both gonadotropins stimulate the production of progesterone by fetal bovine ovaries and that LH specifically stimulates fetal ovarian production of androgens, whereas FSH stimulates their conversion to estradiol. To test these hypotheses, small pieces of fetal ovaries were maintained in organ culture for 10 days in control medium or with $100 \mathrm{ng} / \mathrm{mL} \mathrm{LH,} \mathrm{FSH} \mathrm{or}$ $\mathrm{LH}+\mathrm{FSH}$ in combination, each in the absence or presence of testosterone $(0.5 \mu \mathrm{M})$, and the concentrations of progesterone and estradiol in the culture medium were

Published by Bioscientifica Ltd. 
determined. The concentrations of hormones were chosen based on previous studies on bovine preovulatory follicles (Berndtson et al. 1995a).

Compared with control medium, LH, FSH and $\mathrm{LH}+\mathrm{FSH}$ increased cumulative progesterone by 1.7 - to 3.4-fold (Fig. 1A; $\mathrm{P}<0.05$ ). $\mathrm{LH}$ and $\mathrm{LH}+\mathrm{FSH}$ were both about twice as effective as FSH alone, and there was neither an additive nor a synergistic effect of combining $\mathrm{LH}$ and FSH. In contrast to the effects of gonadotropins, testosterone reduced cumulative progesterone by 97 and $72 \%$, compared with control and $\mathrm{LH}+\mathrm{FSH}$, respectively $(P<0.05)$. During the course of culture, progesterone accumulation in control medium increased between Days 2 and 6 , but plateaued thereafter, whereas exogenous testosterone suppressed progesterone as early as Day 2 and for the duration of culture (Fig. 1B).

Compared with control medium, LH, FSH and $\mathrm{LH}+\mathrm{FSH}$ significantly increased estradiol accumulation over 10 days of culture by 5-, 2- and 7.5-fold, respectively (Fig. 1C). Although LH and FSH both increased estradiol accumulation, $\mathrm{LH}$ and $\mathrm{LH}+\mathrm{FSH}$ were more effective than FSH alone and there was neither an additive nor a synergistic effect of $\mathrm{LH}+\mathrm{FSH}$. Testosterone was much more effective than the gonadotropins alone, increasing estradiol by 25-fold compared with control medium without testosterone $(P<0.05)$. The combination of testosterone $+\mathrm{LH}$ was not different from testosterone alone, but testosterone $+\mathrm{FSH}$ and testosterone $+\mathrm{LH}+\mathrm{FSH}$ approximately doubled the accumulation of estradiol compared with testosterone alone $(P<0.05)$. Analysis of the time course of estradiol production showed that accumulation of estradiol in control cultures decreased from Day 2 to Day 10, but this pattern was reversed in cultures with gonadotropins or testosterone (Fig. 1D). On Day 2 and throughout culture, accumulation of estradiol was much greater in cultures with testosterone than that without testosterone.

\section{Experiment 2: Effects of gonadotropins on the production of androstenedione and testosterone}

Little is known about the regulation of androgen production in fetal bovine ovaries, but we hypothesized that LH stimulates the production of androstenedione and testosterone as precursors for estradiol synthesis. This hypothesis was tested with ovarian pieces from an additional set of fetuses, due to limitations of sample volume in Experiment 1. Fetal ovarian pieces were cultured in control medium or with $100 \mathrm{ng} / \mathrm{mL} \mathrm{LH,} \mathrm{FSH}$ or $\mathrm{LH}+\mathrm{FSH}$.

Treatments had similar effects on the accumulation of androstenedione and testosterone, but concentrations of androstenedione were always much higher than those of testosterone (Fig. 2). LH alone increased the accumulation of both androstenedione (4.6-fold) and testosterone (2.3-fold), whereas FSH and $\mathrm{LH}+\mathrm{FSH}$ were similar to control (Fig. 2A and $\mathrm{C}$ ). This result supported the hypothesis that FSH does not stimulate androgen production, but increases the conversion of androgens to estrogens. To test that hypothesis further, treatments were replicated in combination with the aromatase inhibitor letrozole (Let; $0.25 \mu \mathrm{M}$ ) at the lowest concentration shown in
A
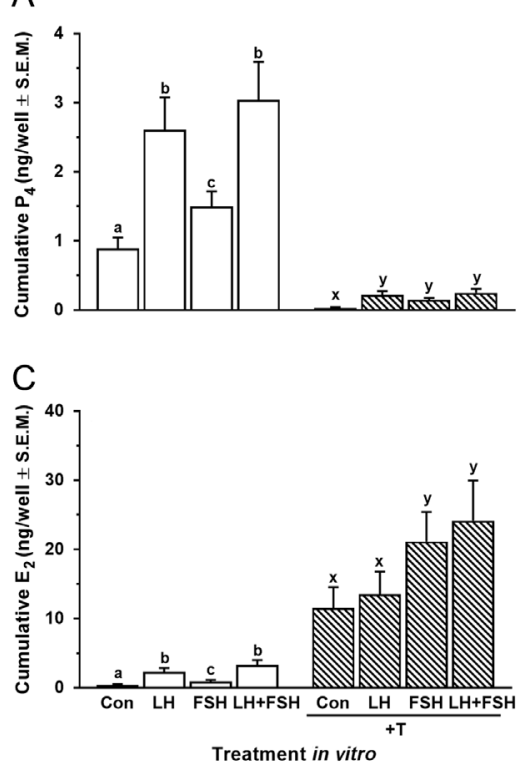

http://jme.endocrinology-journals.org DOI: 10.1530/JME-16-0152

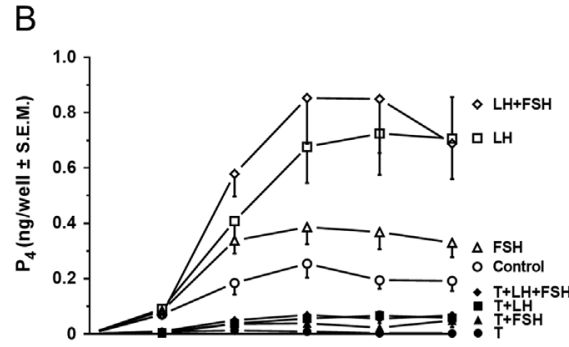

D

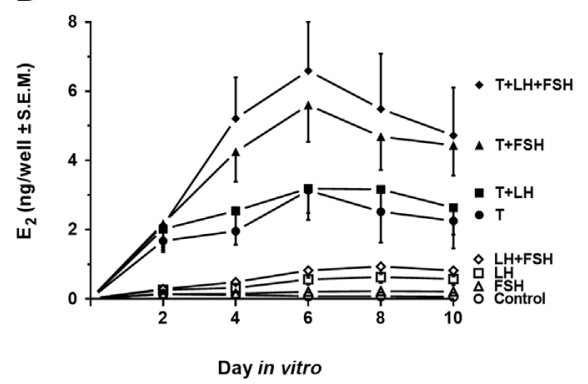

Figure 1

Accumulation of progesterone $\left(\mathrm{P}_{4}\right)$ and estradiol $\left(E_{2}\right)$ in cultures of fetal ovarian pieces over 10 days in control medium (Con) or with $\mathrm{LH}, \mathrm{FSH}$ or $\mathrm{LH}+\mathrm{FSH}(100 \mathrm{ng} / \mathrm{mL})$, each in the absence (open bars) or presence (striped bars) of testosterone $(0.5 \mu \mathrm{M})$. Both cumulative $\mathrm{P}_{4}($ panel $A)$ and $E_{2}$ (panel C) over 10 days and time-courses for $P_{4}$ (panel $B$ ) and $E_{2}$ (panel D) production are shown. Means with no common letters (-testosterone: a-c; +testosterone: $\mathrm{x}, \mathrm{y})$ are different $(P<0.05)$. $n=14$ cultures/treatment; 2 from each of 7 fetuses (81-114 days old). 
A

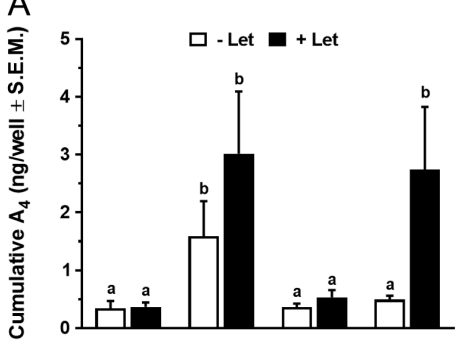

$\mathrm{C}$

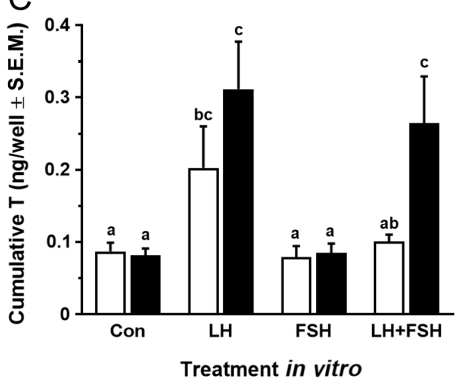

B

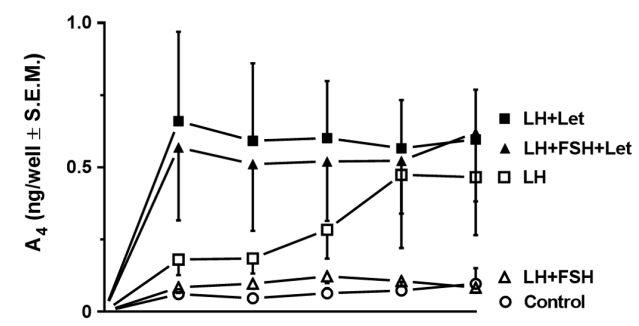

D

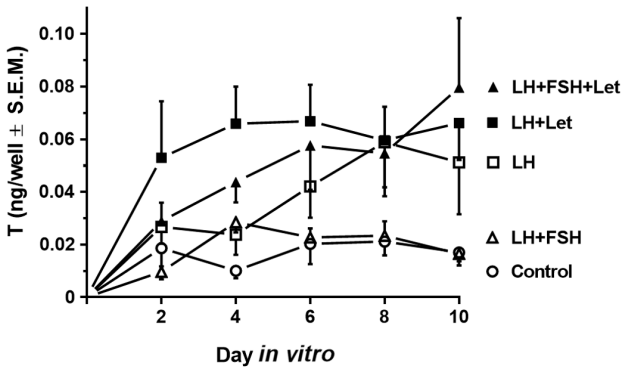

Figure 2

Accumulation of androstenedione $\left(\mathrm{A}_{4}\right)$ and testosterone $(T)$ in cultures of fetal ovarian pieces over 10 days in control medium (Con) or with $\mathrm{LH}$, $\mathrm{FSH}$ or $\mathrm{LH}+\mathrm{FSH}(100 \mathrm{ng} / \mathrm{mL})$, each in the absence or presence of the aromatase inhibitor letrozole (Let; $0.25 \mu \mathrm{M}$ ). Panels $\mathrm{A}$ and $\mathrm{C}$ show cumulative $\mathrm{A}_{4}$ and testosterone over 10 days, respectively, and time-courses are shown in panels B and D. Means within a panel with no common letters are different $(P<0.05) . n=10$ cultures/treatment; 2 from each of 5 fetuses (76-89 days old). dose-response studies to inhibit estradiol production in the presence of testosterone (Supplementary Fig. 1, see section on supplementary data given at the end of this article). In the current experiment, letrozole reduced estradiol to less than $6 \%$ of control values, even when LH and FSH were present (Supplementary Fig. 2). Letrozole alone, Let+LH and Let+FSH had no effect on androstenedione or testosterone accumulation compared with control, $\mathrm{LH}$ and $\mathrm{FSH}$, respectively (Fig. 2A and C). However, the addition of letrozole to cultures with $\mathrm{LH}+\mathrm{FSH}$ dramatically increased both androstenedione and testosterone compared with $\mathrm{LH}+\mathrm{FSH}$ alone, indicating that FSH, not LH, stimulates the aromatization of androgens.

Accumulation of androstenedione and testosterone in control cultures and with $\mathrm{LH}+\mathrm{FSH}$ was low and relatively consistent over time (Fig. 2B and D). Interestingly, letrozole changed the temporal pattern of androgen accumulation in the presence of LH; peak androgen concentrations occurred much earlier in the presence of the aromatase inhibitor. Time-courses for Let alone, FSH alone and Let $+\mathrm{FSH}$ were not different from control and are not shown in Fig. 2B and D to improve clarity.

\section{Experiment 3: Effects of graded doses of LH and FSH on steroid production}

To determine the sensitivity of fetal ovarian tissue to gonadotropins, pieces of fetal bovine ovaries were cultured for 10 days with $0,1,2,10,50$ or $100 \mathrm{ng} / \mathrm{mL} \mathrm{LH} \mathrm{or} \mathrm{FSH.}$ Effects of graded doses of $\mathrm{LH}$ are shown in Fig. 3. All concentrations of LH between 2 and $100 \mathrm{ng} / \mathrm{mL}$ increased the accumulation of steroids relative to control $(P<0.05)$, but $10 \mathrm{ng} / \mathrm{mL} \mathrm{LH}$ was the lowest dose that maximally stimulated progesterone (2.6-fold), androstenedione

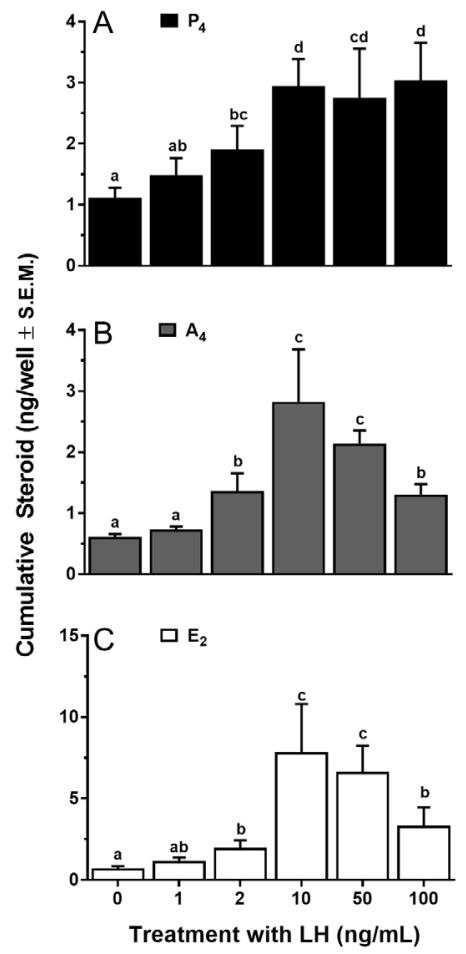

Figure 3

Effects of graded doses of $\mathrm{LH}(0,1,2,10,50$ and $100 \mathrm{ng} / \mathrm{mL})$ on accumulation of progesterone $\left(P_{4} ;\right.$ panel $\left.A\right)$, androstenedione $\left(A_{4} ;\right.$ panel $\left.B\right)$ and estradiol $\left(E_{2} ;\right.$ panel $\left.C\right)$ over 10 days in cultures of fetal bovine ovarian pieces. Within a panel, means with no common letters are different $(P<0.05) . n=10$ cultures/treatment, 2 from each of 5 fetuses (78-107 days old).

Published by Bioscientifica Ltd 
(3.7-fold) and estradiol (10.7-fold). Higher doses of LH (50 and $100 \mathrm{ng} / \mathrm{mL}$ ) maintained maximal concentrations of progesterone, but not androstenedione or estradiol. Thus, the response to $\mathrm{LH}$ was biphasic for both androstenedione and estradiol, but not for progesterone. Testosterone was not measured in this experiment because testosterone accumulation paralleled that of androstenedione in Experiment 2, but at much lower concentrations, and the amount of medium was not sufficient to measure all four steroids.

Figure 4 shows the effects of graded doses of FSH on progesterone and estradiol accumulation. In the absence of testosterone, only the highest dose of FSH $(100 \mathrm{ng} / \mathrm{mL})$ increased the accumulation of both progesterone and estradiol, but $50 \mathrm{ng} / \mathrm{mL}$ also stimulated progesterone maximally ( 2-fold; Fig. $4 \mathrm{~A}$ and B). To determine what concentrations of FSH stimulate the aromatization of exogenous androgen, fetal ovarian
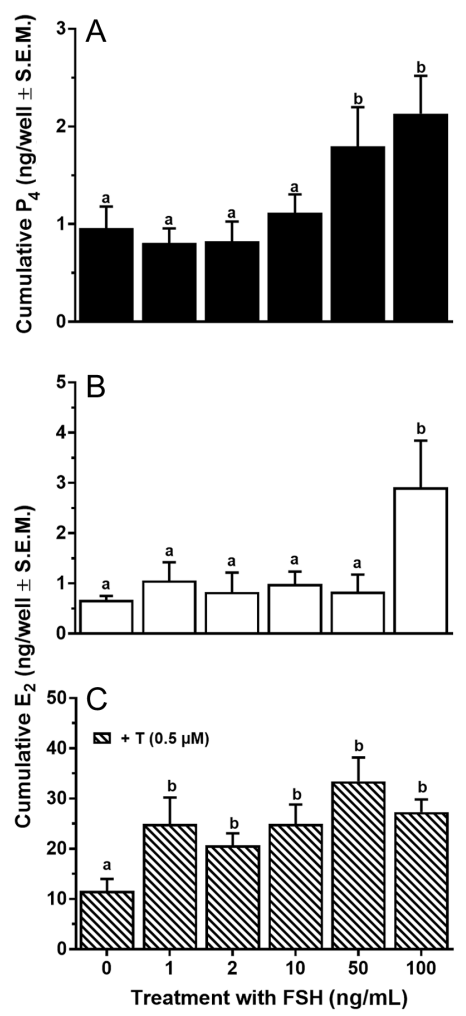

Figure 4

Effects of graded doses of FSH $(0,1,2,10,50$ and $100 \mathrm{ng} / \mathrm{mL})$ on accumulation of progesterone $\left(\mathrm{P}_{4} ;\right.$ panel $\left.\mathrm{A}\right)$ and estradiol $\left(\mathrm{E}_{2} ;\right.$ panel $\left.\mathrm{B}\right)$ over 10 days in cultures of fetal ovarian pieces from each of 3 fetuses (78-99 days old; $n=6$ cultures/treatment). Shown in panel $\mathrm{C}$ is the accumulation of $E_{2}$ over 10 days with testosterone $(T ; 0.5 \mu \mathrm{M})$ and graded doses of FSH based on data from 5 fetuses (78-107 days old; $n=10$ cultures/treatment). Within a panel, means with no common letters are different $(P<0.05)$. pieces were also cultured in medium with testosterone $(0.5 \mu \mathrm{M})$ and the same doses of FSH $(0-100 \mathrm{ng} / \mathrm{mL})$, and the accumulation of estradiol was measured. All concentrations of FSH increased the accumulation of estradiol maximally compared with treatment with testosterone alone (Fig. 4C), indicating that fetal ovaries are quite sensitive to FSH. Androgens were not measured because FSH did not stimulate androgen production in Experiment 2, and the effects of graded doses of FSH on progesterone production were not determined when testosterone was in the medium because testosterone decreased progesterone concentrations so dramatically in Experiment 1.

\section{Experiment 4: Effects of androgens and estradiol on progesterone production}

Unexpectedly, testosterone decreased the accumulation of progesterone in Experiment 1, even when gonadotropins were present (Fig. 1A and B), implying that testosterone inhibits progesterone production. We hypothesized that testosterone inhibits progesterone indirectly through its aromatization to estradiol. As an initial test of this hypothesis, pieces of fetal bovine ovaries were cultured for 10 days in control medium or with $0.5 \mu \mathrm{M}$ testosterone, estradiol or the non-aromatizable androgen DHT, each in the absence or presence of $100 \mathrm{ng} / \mathrm{mL} \mathrm{LH}+\mathrm{FSH}$. As

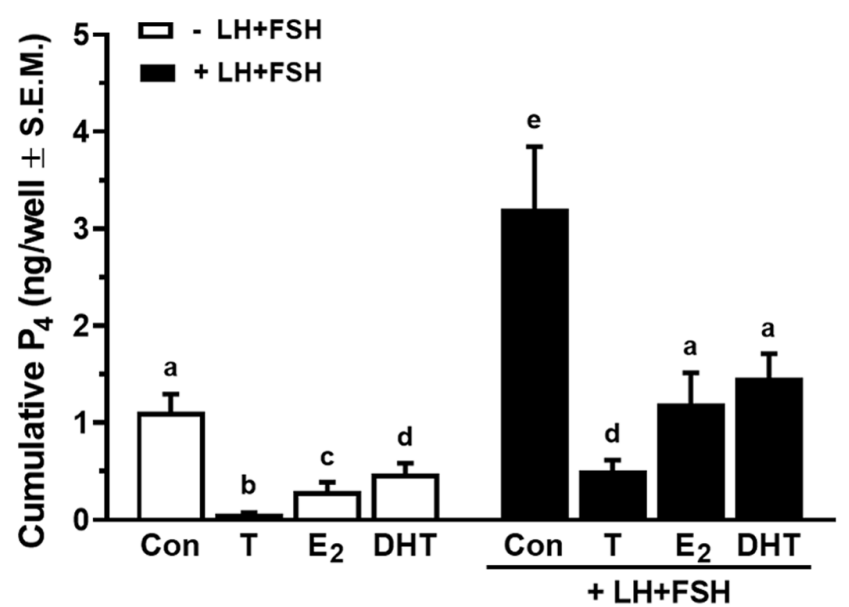

Treatment in vitro

Figure 5

Effects of control medium (Con), testosterone $(T ; 0.5 \mu \mathrm{M})$, estradiol $\left(E_{2} ; 0.5 \mu \mathrm{M}\right)$ and 5-alpha-dihydrotestosterone $(\mathrm{DHT} ; 0.5 \mu \mathrm{M})$, each in the absence or presence of $\mathrm{LH}+\mathrm{FSH}$ (both at $100 \mathrm{ng} / \mathrm{mL}$ ), on the accumulation of progesterone $\left(\mathrm{P}_{4}\right)$ in cultures of fetal ovarian pieces over 10 days. Means with no common letters are different $(P<0.05) . n=12$ cultures/ treatment; 2 from each of 6 fetuses (79-114 days old).

Published by Bioscientifica Ltd 


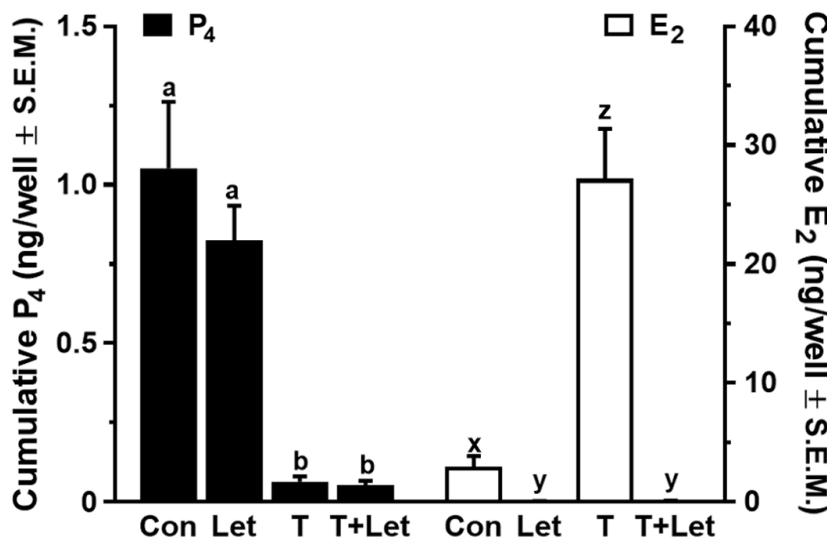

Treatment in vitro

Figure 6

Effects of control medium (Con), letrozole (Let; $0.25 \mu \mathrm{M}$ ), testosterone $(\mathrm{T} ; 0.5 \mu \mathrm{M})$ and Let + testosterone on the accumulation of progesterone $\left(\mathrm{P}_{4} ;\right.$ black bars) and estradiol ( $E_{2}$; open bars) in cultures of fetal ovarian pieces over 10 days. For each steroid, means with no common letters $\left(P_{4}\right.$ : $\left.\mathrm{a}, \mathrm{b} ; \mathrm{E}_{2}: \mathrm{x}-\mathrm{z}\right)$ are different $(P<0.05) . n=6$ cultures/treatment; 2 from each of 3 fetuses (79-89 days old).

expected, testosterone, but not DHT, increased estradiol production (JJ Allen, JE Fortune \& MY Yang unpublished observations), which agrees with previous studies (Shemesh 1980). Accumulation of progesterone over 10 days in control cultures averaged $1.1 \mathrm{ng} /$ well (Fig. 5). Compared with control, treatment with testosterone, estradiol and DHT reduced progesterone accumulation by

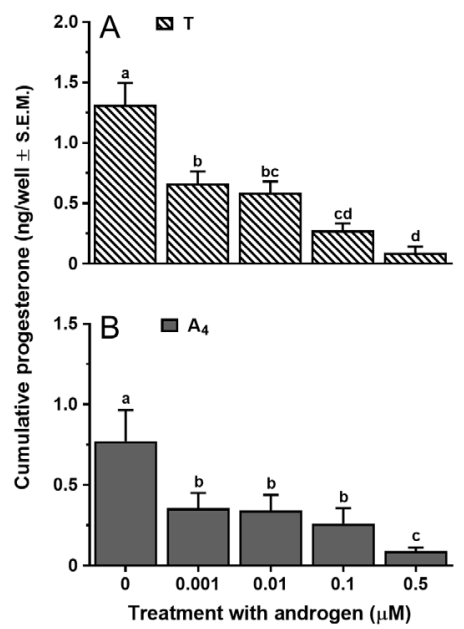

Figure 7

Effects of graded doses of testosterone ( $T$; panel $A$ ) or androstenedione $\left(A_{4} ;\right.$ panel $\left.B\right)$ on cumulative progesterone in cultures of fetal ovarian pieces treated with either androgen at $0,0.001,0.01,0.1$ or $0.5 \mu \mathrm{M}$ for 10 days. Within a panel, means with no common letters are different $(P<0.05) . n=6$ cultures/treatment; 2 from each of 3 fetuses, which were 78-89 (panel A) or 78-94 (panel B) days old.
94, 73 and 57\%, respectively $(P<0.05)$. LH + FSH enhanced progesterone 3 -fold relative to control, but addition of testosterone, estradiol or DHT completely inhibited the stimulation by the gonadotropins. Testosterone was most inhibitory and reduced progesterone by $84 \%$ compared with $\mathrm{LH}+\mathrm{FSH}$, which was well below the concentration in control cultures $(P<0.05)$.

These results indicated that androgen (DHT) and estradiol can inhibit progesterone production independently, but it was still unclear whether the aromatization of testosterone to estradiol is necessary for inhibition by testosterone. To address this question, we cultured fetal ovarian pieces in control medium or with testosterone $(0.5 \mu \mathrm{M})$, in the absence or presence of letrozole $(0.25 \mu \mathrm{M})$ to inhibit aromatase. Cumulative estradiol averaged $3 \mathrm{ng} /$ well in control cultures and was 9-fold greater in the presence of testosterone alone (Fig. 6). However, letrozole reduced the conversion of testosterone to estradiol by about $97 \%(P<0.05)$. Compared with
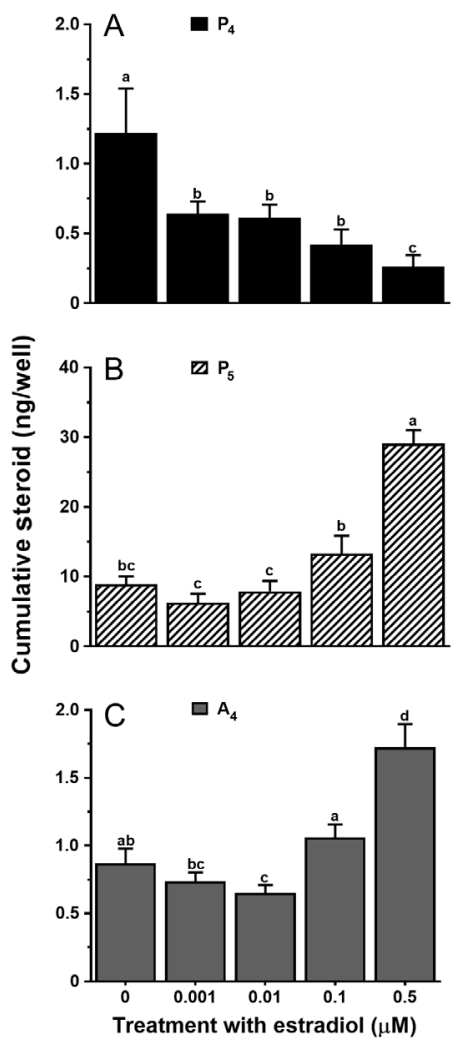

Figure 8

Effects of graded doses of estradiol $\left(E_{2} ; 0,0.001,0.01,0.1\right.$ or $\left.0.5 \mu \mathrm{M}\right)$ on cumulative progesterone $\left(P_{4} ;\right.$ panel $\left.A\right)$, pregnenolone $\left(P_{5} ;\right.$ panel $\left.B\right)$ and androstenedione $\left(A_{4} ;\right.$ panel $\left.C\right)$ in cultures of fetal ovarian pieces over 10 days. Within a panel, means with no common letters are different $(P<0.05) . n=6$ cultures/treatment; 2 from each of 3 fetuses (74-94 days old).

Published by Bioscientifica Ltd 
control, progesterone accumulation was unaffected by letrozole alone, but was significantly reduced by testosterone in the absence or presence of letrozole, indicating that testosterone can inhibit progesterone directly.

\section{Experiment 5: Effects of graded doses of testosterone, androstenedione and estradiol on progesterone production}

The results mentioned previously support the hypothesis that fetal ovarian (endogenous) estradiol, and possibly androgens, are paracrine regulators of progesterone production, but the concentrations of exogenous steroids used in the experiments (about $150 \mathrm{ng} / \mathrm{mL}$ ) are much higher than the concentrations of endogenous steroids measured in cultures of fetal bovine ovarian pieces. To determine if lower concentrations of exogenous steroids can reduce progesterone accumulation, ovarian pieces were cultured in control medium or with graded doses of testosterone, androstenedione or estradiol (0.001, $0.01,0.1$ or $0.5 \mu \mathrm{M}$; i.e. about $0.3-150 \mathrm{ng} / \mathrm{mL}$ ). Each steroid was tested on ovarian tissue from a different set of three fetuses (74-94 days old).

All concentrations of testosterone, androstenedione and estradiol reduced progesterone accumulation relative to control in a dose-dependent fashion $(P<0.05)$, but $0.5 \mu \mathrm{M}$ was maximal, reducing progesterone by 93,88 and 79\%, respectively (Figs 7 and 8A). Pregnenolone and androstenedione were also measured in the estradiol dose-response experiment. Interestingly, the highest dose of estradiol also increased the accumulation of pregnenolone and androstenedione in the same cultures by 3 - and 2 -fold, respectively ( $P<0.05$; Fig. $8 \mathrm{~B}$ and $\mathrm{C})$. This suggested to us that estradiol inhibited the production of progesterone via the $\Delta^{4}$ pathway and promoted fetal ovarian steroidogenesis via the $\Delta^{5}$ pathway (pregnenolone and dehydroepiandrosterone).

\section{Discussion}

Evidence from studies with cattle (Yang \& Fortune 2008, Nilsson \& Skinner 2009) indicates that fetal ovarian (endogenous) progesterone and estradiol are negative regulators of follicle formation and activation in vivo. However, the regulation of steroid production, particularly the role of the gonadotropins, in fetal bovine ovaries during critical periods of early follicular development is poorly understood. This study showed that LH and FSH have differential effects on steroid production by fetal bovine ovarian pieces in vitro and that estradiol also can regulate fetal ovarian steroid production. These novel results for fetal ovarian tissue are remarkably similar to the effects of gonadotropins on steroid production by theca and granulosa cells from bovine preovulatory follicles (i.e. the two-cell, two-gonadotropin model (Fortune \& Quirk 1988)). The inhibition of progesterone production by estradiol that we observed was also noted in studies on follicular cells from bovine preovulatory follicles (Fortune 1986). These results support the hypothesis that LH and FSH target different fetal ovarian cells, with different cell types producing androgens and estrogens. It is possible that mechanisms regulating ovarian steroid production are established during fetal life in cattle and are conserved as ovaries develop. Given the similarity of ovarian development and follicular function in humans and cattle (Campbell et al. 2003), these results could provide a basis for improving the understanding of ovarian development in cattle and women.

Our study in vitro provides insight into the role(s) of gonadotropins in fetal ovarian steroid production in vivo. The concentrations of LH and FSH used in this study are likely to be within physiological range. Low concentrations of LH (2 ng/mL; Fig. 3B) and FSH (1 ng/mL; Fig. 4C) stimulated fetal ovarian androstenedione and estradiol production, respectively. Around 90 days of gestation, circulating concentrations of $\mathrm{LH}$ in female bovine fetuses are about $3 \mathrm{ng} / \mathrm{mL}$ (Oxender et al. 1972b, Challis et al. 1974, Muranishi et al. 2002) and reports on concentrations of FSH vary from about $3 \mathrm{pg} / \mathrm{mL}$ (Tanaka et al. 2001) to $1 \mathrm{ng} / \mathrm{mL}$ (Muranishi et al. 2002). Gonadotropins measured in these studies are likely produced by the fetus because anterior pituitaries from 90-day-old bovine fetuses produced LH in vitro (Oxender et al. 1972a) and because administration of GnRH to 120-day-old bovine fetuses in vivo increased concentrations of LH in fetal circulation without affecting maternal LH (Kiser et al. 1975). Furthermore, concentrations of LH in fetal sera decrease between days 90 and 260, whereas maternal concentrations remain constant (Oxender et al. $1972 b)$, indicating that maternal and fetal gonadotropins are regulated independently.

Our results show that $\mathrm{LH}$, but not FSH, stimulates androgen production by fetal bovine ovarian pieces. LH alone increased the accumulation of both androstenedione and testosterone in the culture medium, whereas FSH alone was without effect, even when conversion of androgens to estrogens was blocked

Published by Bioscientifica Ltd 
by the aromatase inhibitor letrozole (Fig. 2). The combination $\mathrm{LH}+\mathrm{FSH}$ reduced androgen concentrations relative to LH alone, but we hypothesized that this was because FSH stimulated the aromatization of androgens to estradiol. Addition of the aromatase inhibitor letrozole to cultures with $\mathrm{LH}+\mathrm{FSH}$ increased androgen accumulation to the same degree as LH alone (Fig. 2), confirming this hypothesis. Concentrations of LH between 2 and $100 \mathrm{ng} / \mathrm{mL}$ increased androstenedione accumulation (Fig. 3), indicating that fetal bovine ovaries are sensitive to very low doses of LH. In general, these results are in agreement with the effects of $\mathrm{LH}$ on androstenedione production by whole fetal porcine ovaries maintained in organ culture (Raeside 1983). The production of androstenedione was consistently greater than testosterone, even when estradiol production was inhibited (Fig. 2). Dominguez and coworkers (Dominguez et al. 1988) found that the accumulation of androstenedione and estrone in cultures of fetal bovine ovarian pieces (75-125 days old) was greater than testosterone and estradiol, respectively. Together, these results indicate that androstenedione is the major androgen produced by fetal bovine ovaries and that estradiol production occurs predominantly through conversion of androstenedione to estrone and subsequent conversion of estrone to estradiol. Interestingly, Shemesh (1980) suggested that androgen substrate becomes limiting to ovarian estradiol production in bovine fetuses older than about 90 days of gestation, which is when the capacity of fetal bovine ovaries to produce estradiol decreases dramatically (Dominguez et al. 1988, Yang \& Fortune 2008, Nilsson \& Skinner 2009). Because LH stimulated androgen production in this study, it seems possible that decreased fetal LH production after 90 days of gestation (Oxender et al. 1972b) may cause decreased fetal ovarian androgen (and progesterone) production and a subsequent decrease in estradiol synthesis.

Addition of androgen precursor (testosterone) to cultures of fetal ovarian pieces dramatically increased the production of estradiol. Combination of testosterone with FSH, but not LH, increased aromatization, and the combination of $\mathrm{LH}+\mathrm{FSH}$ was not different from $\mathrm{FSH}$ alone (Fig. 1B and D). FSH (and $\mathrm{LH}+\mathrm{FSH}$ ) also increased estradiol accumulation in the absence of added androgen. Although LH increased estradiol in the absence of exogenous androgen and enhanced the small effect of FSH alone, this can be attributed to aromatization of the increased androgens stimulated by LH, rather than a direct effect on aromatization. Compared with LH alone, the combination $\mathrm{LH}+\mathrm{FSH}$ reduced androgens (Fig. 2A and $\mathrm{C}$ ), but maintained increased concentrations of estradiol within the same cultures (Supplementary Fig. 2), providing additional evidence that only FSH stimulates the conversion of androgens to estrogens. In further support of this, combination of letrozole with $\mathrm{LH}+\mathrm{FSH}$ reversed the effects of FSH; estradiol was reduced (Supplementary Fig. 2) and concentrations of androgens were increased relative to LH+FSH (Fig. 2). In the presence of testosterone, concentrations of FSH as low as $1 \mathrm{ng} / \mathrm{mL}$ increased estradiol accumulation maximally (Fig. 4C), indicating that fetal ovaries are very sensitive to FSH. Studies with other mammals showed that FSH can regulate the production of fetal ovarian estrogens with or without exogenous androgen present (reviewed in George \& Wilson 1979, Weniger 1990), which is in agreement with our results.

Both LH and FSH increased progesterone accumulation, but LH alone was more effective than FSH alone (Fig. 1A), possibly because LH increased progesterone as a precursor for androgen production, whereas FSH primarily affected the aromatization of androgens to estrogens. There was neither an additive nor a synergistic effect of the combination $\mathrm{LH}+\mathrm{FSH}$, which was similar to LH alone. Furthermore, a low dose of LH $(2 \mathrm{ng} / \mathrm{mL})$ stimulated progesterone and the effect of LH was maximal at $10 \mathrm{ng} / \mathrm{mL}$ (Fig. 3A), whereas the lowest effective dose of FSH was 25 times higher (50 ng/mL; Fig. 4A). Interestingly, the highest dose of LH maintained maximal concentrations of progesterone, but not androstenedione or estradiol, which is consistent with the effects of low and high doses of LH on steroid production by follicle cells from bovine preovulatory follicles (Berndtson et al. 1995a,b). Addition of $\mathrm{LH}$ $(1 \mu \mathrm{g} / \mathrm{mL})$ to 24 -h cultures of fetal bovine ovarian pieces did not increase progesterone accumulation in a previous study (Shemesh et al. 1978), but the concentration of LH used and the duration of culture were quite different from this study, so this discrepancy is not surprising. Because progesterone production by fetal bovine testes and ovaries begins before the sexually dimorphic patterns of androgen and estrogen production, respectively (Shemesh et al. 1978, Shemesh \& Hansel 1983), there may be a role for progesterone in early gonadal development.

Although fetal bovine ovaries are clearly responsive to LH and FSH at the ages used in this study (74-114 days), it remains unclear which cells produce steroids in response to gonadotropins. Binding sites for LH were localized to theca cells of early antral follicles and binding sites for FSH to granulosa cells of primary, secondary

Published by Bioscientifica Ltd 
and early antral follicles in fetal bovine ovaries between 120 and 260 days of gestation (Wandji et al. 1992), but younger ovaries have not been examined. Theca cells are not present in fetal ovaries at the ages used in our study, but androgen production appears to predominate in the medulla of younger ovaries (45-75 days old) because cells isolated from the medulla synthesized androstenedione and testosterone from radioactive precursors at greater rates than did cells from the ovarian cortex (JuarezOropeza et al. 1993). Follicles (and granulosa cells) are absent from fetal ovaries before 90 days of gestation, yet steroid production is most robust before 90 days (Dominguez et al. 1988, Yang \& Fortune 2008, Nilsson \& Skinner 2009). Furthermore, aromatase was not associated with primordial follicles in immunohistochemical studies (Burkhart et al. 2010, Garverick et al. 2010), so it remains unclear which cells produce steroids in response to FSH at the ages in this study (74-114 days). At 45 and 60 days, mRNA and protein for aromatase were found generally throughout the ovary, but localization becomes increasingly restricted to the cell streams and/ or rete tubules of the medulla between 75 and 105 days of gestation (Garverick et al. 2010). If androgen production is predominately in the medulla as suspected, it makes sense that aromatase, and thus production of estrogens, would also predominate in the medulla.

Although our initial objective was to study the effects of gonadotropins on fetal steroidogenesis, we found, unexpectedly, that both androgens and estradiol decreased progesterone accumulation in cultures of fetal bovine ovarian pieces, in the absence and presence of gonadotropins. The effects of androgens appear to be direct, rather than indirect through conversion to estradiol because the non-aromatizable androgen DHT decreased progesterone accumulation (Fig. 5) and testosterone inhibited progesterone production, even when its conversion to estradiol was blocked by letrozole (Fig. 6). Concentrations of endogenous androgen in vivo are unlikely to reach concentrations that were inhibitory to progesterone production in vitro. However, the accumulation of estradiol in the culture medium could be increased to a maximum of about $20 \mathrm{ng} / \mathrm{mL}$ (Fig. 1D), which is within the range of the concentrations that were inhibitory when estradiol was given exogenously ( $\sim .3-$ $150 \mathrm{ng} / \mathrm{mL}$ ). Interestingly, the highest dose of exogenous estradiol $(0.5 \mu \mathrm{M})$ not only decreased progesterone accumulation, but also increased pregnenolone and androstenedione in the same cultures (Fig. 8), indicating that estradiol blocked the conversion of pregnenolone to progesterone by the enzyme $3 \beta$-HSD ( $\Delta^{4}$ pathway of steroid synthesis), but promoted the conversion of pregnenolone to androgen precursors by the enzyme CYP17A1 ( $\Delta^{5}$ pathway). The $\Delta^{5}$ pathway appears to be the predominant pathway used by fetal bovine ovaries because cumulative pregnenolone and androstenedione in control cultures were about 7 and 4 times greater than progesterone and testosterone, respectively (Figs 2 and 8). Estradiol also inhibited progesterone production by granulosa and theca cells of bovine preovulatory follicles, but increased pregnenolone and androstenedione production (Fortune \& Hansel 1979a,b), supporting the hypothesis that estradiol is a paracrine regulator of steroid production in both fetal and adult ovarian tissue. There are multiple isoforms of $3 \beta-\mathrm{HSD}$, the enzyme that converts $\Delta^{5}$ steroids, like pregnenolone and dehydroepiandrosterone, to $\Delta^{4}$ steroids, like progesterone and androstenedione (Miller 2008), and this may explain the differential effects of estradiol on progesterone and androstenedione production. Progesterone can inhibit follicle formation and activation directly ( $\mathrm{M}$ Yang and J Fortune, unpublished observations), and the pattern of progesterone production in fetal bovine ovaries is distinct from that of estradiol (Yang \& Fortune 2008), so factors that differentially regulate progesterone and estradiol production are of interest.

Studies in vitro have provided evidence that ovarian progesterone and estradiol regulate early bovine follicular development, so it is imperative to understand how fetal steroid production is regulated. Results of this study showed that physiological concentrations of gonadotropins had differential effects on androgen (LH) and estradiol (FSH) production by fetal bovine ovarian tissue in vitro and that progestin production can be modulated by estradiol. The similarities between adult and fetal ovarian steroid production in cattle may indicate that mechanisms that regulate steroid production are established during fetal life; disrupting these mechanisms during early development may impinge on adult ovarian function. These novel findings for bovine ovaries may improve our understanding of follicular development in other mammalian species, such as humans and sheep, where early follicular development is also difficult to study.

\section{Supplementary data}

This is linked to the online version of the paper at http://dx.doi.org/10.1530/ JME-16-0152.

\section{Declaration of interest}

The authors declare that there is no conflict of interest that could be perceived as prejudicing the impartiality of the research reported.

Published by Bioscientifica Ltd 


\section{Funding}

This work was supported by National Research Initiative Competitive grant no. 2008-35203-05989 from the USDA National Institute of Food and Agriculture and by the USDA National Institute of Food and Agriculture, Multistate project NE-1227. Any opinions, findings, conclusions or recommendations expressed in this publication are those of the author(s) and do not necessarily reflect the view of the National Institute of Food and Agriculture (NIFA) or the United States Department of Agriculture (USDA).

\section{Author contribution statement}

J J A and JE F were involved in the conception and design of experiments. J J A and S L H performed the experiments. J J A, S L H and J E F interpreted the results of experiments. J J A prepared figures and J J A and J E F wrote the manuscript. The manuscript has been approved by all authors.

\section{Acknowledgements}

The authors thank Drs G Niswender, T Nett and D Armstrong for donating the antibodies used for radioimmunoassays and the National Hormone and Pituitary Program NIDDK, NIH, USA for the LH and FSH used in this study. The authors also thank Drs R Gilbert and S Suarez for reading the manuscript and for helpful suggestions.

\section{References}

Baker TG 1963 A quantitative and cytological study of germ cells in human ovaries. Proceedings of the Royal Society of London: Series B, Biological Sciences 158 417-433. (doi:10.1098/rspb.1963.0055)

Berndtson AK, Vincent SE \& Fortune JE 1995a Effects of gonadotrophin concentration on hormone production by theca interna and granulosa cells from bovine preovulatory follicles. Journal of Reproduction and Fertility 49 (Supplement) 527-531.

Berndtson AK, Vincent SE \& Fortune JE 1995b Low and high concentrations of gonadotropins differentially regulate hormone production by theca interna and granulosa cells from bovine preovulatory follicles. Biology of Reproduction 52 1334-1342. (doi:10.1095/biolreprod52.6.1334)

Burkhart MN, Juengel JL, Smith PR, Heath DA, Perry GA, Smith MF \& Garverick HA 2010 Morphological development and characterization of aromatase and estrogen receptors alpha and beta in fetal ovaries of cattle from days 110 to 250. Animal Reproduction Sciences $\mathbf{1 1 7}$ 43-54. (doi:10.1016/j.anireprosci.2009.02.010)

Campbell BK, Souza C, Gong J, Webb R, Kendall N, Marsters P, Robinson G, Mitchell A, Telfer EE \& Baird DT 2003 Domestic ruminants as models for the elucidation of the mechanisms controlling ovarian follicle development in humans. Reproduction Supplement 61 429-443.

Challis JR, Kim CK, Naftolin F, Judd HL, Yen SS \& Benirschke K 1974 The concentrations of androgens, oestrogens, progesterone and luteinizing hormone in the serum of foetal calves throughout the course of gestation. Journal of Endocrinology 60 107-115. (doi:10.1677/joe.0.0600107)

Chen Y, Jefferson WN, Newbold RR, Padilla-Banks E \& Pepling ME 2007 Estradiol, progesterone, and genistein inhibit oocyte nest breakdown and primordial follicle assembly in the neonatal mouse ovary in vitro and in vivo. Endocrinology 148 3580-3590. (doi:10.1210/ en.2007-0088)

Dominguez MM, Liptrap RM \& Basrur PK 1988 Steroidogenesis in fetal bovine gonads. Canadian Journal of Veterinary Research 52 401-406.

Erickson BH 1966 Development and radio-response of the prenatal bovine ovary. Reproduction 11 97-105. (doi:10.1530/jrf.0.0110097)
Fortune JE 1986 Bovine theca and granulosa cells interact to promote androgen production. Biology of Reproduction 35 292-299. (doi:10.1095/biolreprod35.2.292)

Fortune JE \& Eppig JJ 1979 Effects of gonadotropins on steroid secretion by infantile and juvenile mouse ovaries in vitro. Endocrinology 105 760-768. (doi:10.1210/endo-105-3-760)

Fortune JE \& Hansel W 1979a The effects of 17 beta-estradiol on progesterone secretion by bovine theca and granulosa cells. Endocrinology 104 1834-1838. (doi:10.1210/endo-104-6-1834)

Fortune JE \& Hansel W $1979 b$ Modulation of thecal progesterone secretion by estradiol-17 beta. Advances in Experimental Medicine and Biology 112 203-208.

Fortune JE \& Hansel W 1985 Concentrations of steroids and gonadotropins in follicular fluid from normal heifers and heifers primed for superovulation. Biology of Reproduction 32 1069-1079. (doi:10.1095/biolreprod32.5.1069)

Fortune J \& Quirk S 1988 Regulation of steroidogenesis in bovine preovulatory follicles. Journal of Animal Science 66 1-8. (doi:10.2527/ jas1988.6611)

Fortune JE, Yang MY \& Muruvi W 2010 The earliest stages of follicular development: follicle formation and activation. Society of Reproduction and Fertility Supplement 67 203-216.

Garverick HA, Juengel JL, Smith P, Heath DA, Burkhart MN, Perry GA, Smith MF \& McNatty KP 2010 Development of the ovary and ontongeny of mRNA and protein for P450 aromatase (arom) and estrogen receptors (ER) alpha and beta during early fetal life in cattle. Animal Reproduction Sciences 117 24-33. (doi:10.1016/ j.anireprosci.2009.05.004)

George F \& Wilson J 1979 The regulation of androgen and estrogen formation in fetal gonads. Annales de Biologie Animale, Biochimie, Biophysique 19 1297-1306. (doi:10.1051/rnd:19790814)

Juarez-Oropeza MA, Alvarez-Fernandez G, Lopez V, Kawa S \& Pedernera E 1993 Steroid metabolism in the cortex and the medulla of the early fetal bovine ovary. Journal of Experimental Zoology 266 102-107. (doi:10.1002/jez.1402660204)

Kezele P \& Skinner MK 2003 Regulation of ovarian primordial follicle assembly and development by estrogen and progesterone: endocrine model of follicle assembly. Endocrinology 144 3329-3337. (doi:10.1210/en.2002-0131)

Kiser TE, Convey EM, Lin YC \& Oxender WD 1975 Luteinizing hormone and androgens in the bovine fetus after gonadotropinreleasing hormone. Proceedings of the Society for Experimental Biology and Medicine 149 785-789. (doi:10.3181/00379727-14938899)

Miller WL 2008 Steroidogenic enzymes. Endocrine Development 13 1-18. (doi:10.1097/01.ten.0000080298.43106.52)

Muranishi Y, Acosta TJ, Miyamoto A \& Fukui Y 2002 Changes in the number of preantral follicles and hormone concentrations in the bovine fetus. Journal of Reproduction and Development 48 553-560. (doi:10.1262/jrd.48.553)

Nilsson EE \& Skinner MK 2009 Progesterone regulation of primordial follicle assembly in bovine fetal ovaries. Molecular and Cellular Endocrinology 313 9-16. (doi:10.1016/j.mce.2009.09.004)

Oxender WD, Convey EM \& Hafs HD 1972a Bovine fetal pituitary concentration and in vitro synthesis of prolactin, GH, and LH. Proceedings of the Society for Experimental Biology and Medicine 139 1017-1021. (doi:10.3181/00379727-139-36288)

Oxender WD, Hafs HD \& Ingalls WG $1972 b$ Serum growth hormone, LH and prolactin in the bovine fetus and neonate. Journal of Animal Science 35 56-61. (doi:10.2527/jas1972.35156x)

Pepling ME 2006 From primordial germ cell to primordial follicle: mammalian female germ cell development. Genesis 44 622-632. (doi:10.1002/dvg.20258)

Raeside JI 1983 Gonadotrophic stimulation of androgen secretion by the early fetal pig ovary in organ culture. Biology of Reproduction $\mathbf{2 8}$ 128-133. (doi:10.1095/biolreprod28.1.128) http://jme.endocrinology-journals.org

DOI: 10.1530/JME-16-0152
๑) 2016 Society for Endocrinology Printed in Great Britain 
Rexroad CE Jr, Casida LE \& Tyler WJ 1974 Crown-rump length of fetuses in purebred Holstein-Friesian cows. Journal of Dairy Science $\mathbf{5 7}$ 346-347. (doi:10.3168/jds.S0022-0302(74)84891-5)

Russe I 1983 Oogenesis in cattle and sheep. Bibliotheca Anatomica 24 77-92.

Sawyer HR, Smith P, Heath DA, Juengel JL, Wakefield SJ \& McNatty KP 2002 Formation of ovarian follicles during fetal development in sheep. Biology of Reproduction 66 1134-1150. (doi:10.1095/ biolreprod66.4.1134)

Shemesh M 1980 Estradiol-17 beta biosynthesis by the early bovine fetal ovary during the active and refractory phases. Biology of Reproduction 23 577-582. (doi:10.1095/biolreprod23.3.577)

Shemesh M \& Hansel W 1983 Hormone production by the early bovine embryo. Journal of Steroid Biochemistry 19 979-983. (doi:10.1016/0022-4731(83)90043-2)

Shemesh M, Allenberg M, Milaguir F, Ayalon N \& Hansel W 1978 Hormone secretion by cultured bovine pre- and postimplantation gonads. Biology of Reproduction 19 761-767. (doi:10.1095/ biolreprod19.4.761)
Tanaka Y, Nakada K, Moriyoshi M \& Sawamukai Y 2001 Appearance and number of follicles and change in the concentration of serum FSH in female bovine fetuses. Reproduction 121 777-782. (doi:10.1530/ rep.0.1210777)

Wandji SA, Pelletier G \& Sirard MA 1992 Ontogeny and cellular localization of 125I-labeled insulin-like growth factor-I, 125I-labeled follicle-stimulating hormone, and 125I-labeled human chorionic gonadotropin binding sites in ovaries from bovine fetuses and neonatal calves. Biology of Reproduction 47 814-822. (doi:10.1095/ biolreprod47.5.814)

Wandji SA, Srsen V, Voss AK, Eppig JJ \& Fortune JE 1996 Initiation in vitro of growth of bovine primordial follicles. Biology of Reproduction 55 942-948. (doi:10.1095/biolreprod55.5.942)

Weniger JP 1990 Aromatase activity in fetal gonads of mammals. Journal of Developmental Physiology 14 303-306.

Yang MY \& Fortune JE 2008 The capacity of primordial follicles in fetal bovine ovaries to initiate growth in vitro develops during midgestation and is associated with meiotic arrest of oocytes. Biology of Reproduction 78 1153-1161. (doi:10.1095/biolreprod.107.066688)

Received in final form 26 September 2016

Accepted 3 October 2016

Accepted Preprint published online 3 October 2016 